\title{
Ability of School Teachers to Manage Asthmatic Attacks Among School Going Children in Jordan
}

\author{
Mariam M. Kawafha ${ }^{1}$ \\ ${ }^{1}$ Associate Professor, Irbid National University, Irbid, Jordan \\ Correspondence: Mariam M. Kawafha, Associate Professor, Irbid National University, Irbid, Jordan. E-mail: \\ mariamsltn204@gmail.com
}

Received: February 25, 2018 Accepted: March 29, 2018 Online Published: April 4, 2018

doi:10.5539/gjhs.v10n5p55 URL: https://doi.org/10.5539/gjhs.v10n5p55

\begin{abstract}
Background: Chronic asthma has been characterized by recurrent episodes of wheezing and breathing. However, the frequency and severity of the disease vary from one person to another.
\end{abstract}

Purpose: The study aims to assess the ability of school teachers for providing appropriate mediation for the students, who suffer asthmatic attack at school.

Design: The study has incorporated descriptive cross sectional quantitative research design to investigate the capability of school teachers in managing asthmatic attack among children.

Methods: Teachers from primary schools have been recruited by using cluster random sample, and a structured questionnaire has been used for data collection. The data acquired from the questionnaire was analyzed using SPSS version 20.0.

Results: The results showed that the teachers lack awareness about asthma and unable to manage students with asthma. None of the teachers had received educational conference or workshop about asthma.

Conclusion: The study has concluded that the level of knowledge of school teachers regarding asthma is limited and not satisfactory; and teachers are also unable to take care for students with asthma.

Keywords: asthma, Jordan, nurses, school children, teachers

\section{Introduction}

According to United States Department of Health and Human Services (USDHH) and Centers for Disease Control and Prevention (CDC), one in every eleven children have asthma, which result in 5000 deaths annually (USDHH, CDC, 2016). Asthma is taken into account as a chronic disease with no proper cure and have severe impact on the health of millions of people all around the world. The global prevalence is $5-10 \%$; whereas, in Jordan its prevalence is $8.8 \%$ (Reddel, Hurd, \& FitzGerald, 2014). Despite of the fact that there are proper guidelines regarding asthma, there are many patients, who are still in poor condition. It is due to their lack of awareness in terms of asthma treatment and inhaler techniques (Basheti, Hamadi, \& Reddel, 2016).

Chronic illness has a negative impact on the educational experience of the children. Due to asthma, the children are likely to miss more than 12 million days of school. The learning, growing, and development phases of the students have been compromised, when breathing ability and vital body functions are negatively affected (Patterson, 2014). In majority of the developing countries, asthma is considered as a widespread respiratory complication, which is known as a severe type of allergy that can occur in any phase of life (Kawafha \& Tawalbeh, 2015).

The children, suffering from asthma, are affected in various ways depending upon how well the illness is managed. The factors that trigger asthmatic attack include aerosol dust particles, classroom pets, or stuffed animals. A child, when exposed to one of the factors triggering asthma, can be escalated into a full-blown asthma quickly, if immediate management is not provided to the child (Patterson, 2014). The asthma care for students may be jeopardized, if a school fails to offer school health nurses or provide proper knowledge and training to the teachers about management of an asthma attack.

Knowledge alone cannot enhance healthy lifestyle; therefore, it is necessary for school nurses to be available at school for identifying and managing asthma cases properly (Kawafha \& Tawalbeh, 2015). The school nurses are responsible for providing a healthy school environment; but unfortunately, in Jordan; the school nurses are not 
available at schools and do not have any role there. Therefore, it has become necessary for the school teachers to be knowledgeable enough to help children in the case of asthmatic attack. Thus; this study aimed to investigate the ability of elementary school teachers in managing asthmatic attack among students at school.

\section{Methodology}

2.1 Design

A descriptive cross sectional quantitative research design was used to investigate the ability of elementary school teachers in managing asthmatic attack among the students at school.

\subsection{Sample and Setting}

All primary schools for male students in northern Jordan were recruited. It has been evaluated from epidemiological evidences that there is a variation in severity and prevalence of asthma due to gender. Asthma hospitalization, severity, mortality, incidence, prevalence, and exacerbation rate among females is higher as compared to males, above the age of 14 years. However, emergency visit and asthma hospitalization are higher for males than female, under the age 14 years (Patel et al., 2014). The study has obtained cluster random sample from public primary schools in northern Jordan. All teachers in those schools, aged above 18 and agreed to participate, were included. The teachers, having asthma and who attended the educational program concerning asthma, were excluded from the study.

The population of Northern Jordan is 1.8 million, which has been considered as the second largest populated region in Jordan. The rural and urban areas within Jordan belong to different socio-economic status. According to the World Bank (2014), the enrollment of children in Northern region of Jordan was more than $99 \%$. The total number of schools existing in Northern Jordan is 1041 and about 30782 teachers work and teach the students (Ministry of Education, 2017). The proportionate stratified random sampling method was chosen. Because the population density varies within the governorates of northern Jordan. Therefore; the researcher selected teachers with proportion of $10 \%$ from each school. The result was a random selection of 4000 teachers from all schools in northern Jordan.

\subsection{Questionnaire and Data Collection}

Knowledge regarding asthma was measured with the help of Asthma General Knowledge Questionnaire for Adults (AGKQA) to determine the impact of asthma education program on school teachers as well as their ability to tackle asthmatic attack among children. This questionnaire was concerned with knowledge and management of asthma that evaluates the ability of teachers to manage school children suffering asthma. 31 items related to knowledge regarding asthma have been included in AGKQA. These items included pathophysiology, severity of attack, etiology, medications, and management of systems. Each item statement of knowledge was answered by the teachers using True/False/Not Sure.

The option 'Not Sure' was incorrect as it was responsible for discouraging guessing. A number of correct responses was totaled to compute the overall knowledge scores of the teachers. The average range was between $1-31$; whereas, the higher scores referred to better knowledge regarding asthma and its management. The tool developer was asked for permission to use the instrument knowledge. A committee comprising of 4 experts was responsible for reviewing the translated and original instrument. Among the 4 experts, two were competent in Arabic as well as English that is considered equivalent in terms of cultural adaptation and clarity. Whereas, the remaining two were expert in the field of medicine. Modifications were made on the recommendations given by the experts. However, no significant discrepancy was observed between the translated and original version.

The 4 experts confirmed validity of the tool by performing the face validity test. The content validity test was performed and the content validity index was calculated to be 0.89 , which confirmed the validity of the tool, used in this study. The present study also tested the items or internal consistency, and the reliability of Cronbach's alpha was calculated to be 0.85 . Pilot study was conducted among the teachers with similar characteristics as the teachers included in the main sample. The results revealed that the items used in the questionnaire were clear and the researcher faced no problems while administering, coding, scoring, and analyzing the items. Each teacher required 20 minutes to complete the questionnaire.

The knowledge was scored as follows; if the correct answer of the knowledge questionnaire scored $\leq 50 \%$ inadequate knowledge, $51-69 \%$ moderately adequate, $\geq 70 \%$ adequate knowledge. Test scenario was another approach to evaluate the ability of teachers about asthma management. The items were constructed on the basis of Asthma Foundations (Asthma Australia, 2018) and National Asthma Council Australia (National Asthma Council Australia, 2018) (Table 1). 
Table 1. Test Scenario Items

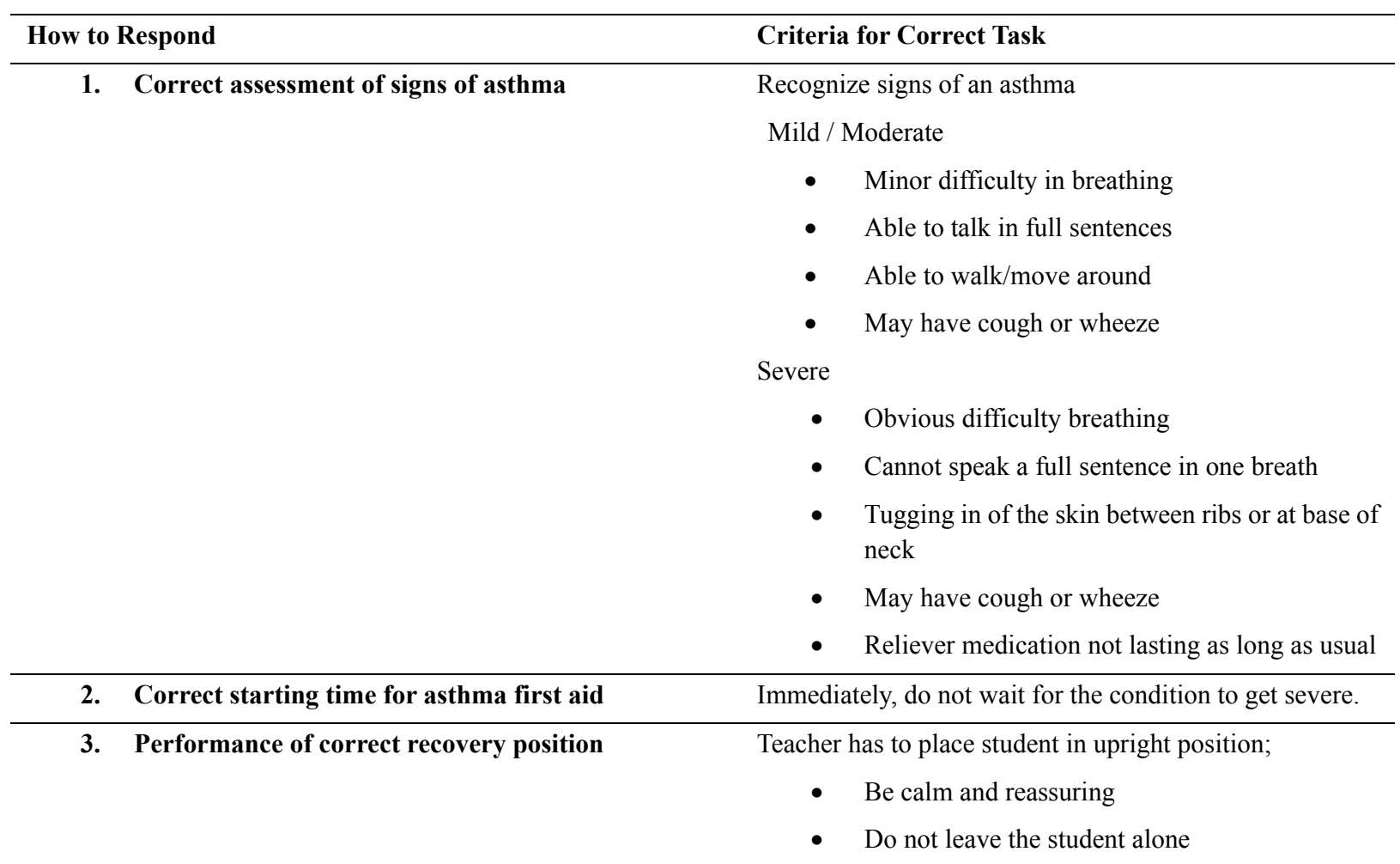

4. Correct Usage of puffer
Give 4 separate puffs of reliever puffer;

- $\quad$ Shake puffer

- Put 1 puff into spacer

- $\quad$ Take 4 breaths from spacer

Repeat until 4 puffs have been taken;

- $\quad$ Shake, 1 puff, 4 breaths
Wait 4 minutes

If there is no improvement, give 4 more separate puffs of blue/grey reliever as above

Immediately call Emergency Assistance.

Keep giving 4 separate puffs every 4 minute until emergency assistance arrives

7. Giving correct information for the emergency call
The teacher need to give correct information to the dispatcher

\subsection{Ethical Consideration}

The data collection instrument was based on the knowledge, skills, and management measures of asthma. The questionnaire was kept safe, which comprised of the demographic profiles and other relevant questions of asthma in an envelope. The study was initially approved by the ethics committee at the Ministry of Education, Jordan. An informed consent form was also signed by the participants of the study.

\subsection{Data Analysis}

The data collected through the questionnaires was analyzed through SPSS version 20 to analyze data of elementary school teachers regarding asthma knowledge. An alpha level of $\leq 0.05$.was considered statistically significant for all analyses. 


\section{Results}

Four thousand teachers were selected by cluster random sampling method. The mean age of the teachers recruited in the study was 39 years $(\mathrm{SD}=6.24)$ and the mean monthly income for the whole sample was 830 Jordan Dinar $(\mathrm{SD}=135.12)$, the average $45.1 \%$ occupational experience was between 11-15 years. None of the recruited participants had received an educational workshop or conference about asthma. Majority (96\%) of teachers were Muslims; while, only 4\% of them were Christian and all of teachers did not have asthma in their family. One of the questions asked the participants if they have adequate knowledge about asthma: "do you think that you have adequate knowledge about asthma?." 70.6\% answered that they have adequate knowledge and 20.4\% have inadequate knowledge.

Table 2. Descriptive Characteristics of the study participants (elementary school teachers) $(n=4000)$

\begin{tabular}{|c|c|c|}
\hline Variables & $\mathbf{n}$ & $\%$ \\
\hline \multicolumn{3}{|c|}{ Age group (y) } \\
\hline$\leq 29$ & 1324 & $33.1 \%$ \\
\hline 30-39 & 1428 & $35.7 \%$ \\
\hline $40-49$ & 379 & $8.8 \%$ \\
\hline$\geq \mathbf{5 0}$ & 869 & $22.4 \%$ \\
\hline \multicolumn{3}{|c|}{ Occupational experience (y) } \\
\hline $1-5$ & 324 & $8.1 \%$ \\
\hline $6-10$ & 740 & $18.5 \%$ \\
\hline $11-15$ & 1804 & $45.1 \%$ \\
\hline $16-20$ & 352 & $8.8 \%$ \\
\hline$\geq 20$ & 780 & $19.5 \%$ \\
\hline \multicolumn{3}{|c|}{ Monthly Income (\$) } \\
\hline$\leq 200$ & 480 & $12 \%$ \\
\hline $201-400$ & 716 & $17.9 \%$ \\
\hline $401-600$ & 1596 & $39.9 \%$ \\
\hline $601-800$ & 312 & $7.8 \%$ \\
\hline 801-1000 & 416 & $10.4 \%$ \\
\hline$\geq 1000$ & 480 & $12 \%$ \\
\hline \multicolumn{3}{|c|}{ Information Adequacy about Asthma (personal statement) } \\
\hline Adequate & 2824 & 70.6 \\
\hline Inadequate & 1176 & 20.4 \\
\hline
\end{tabular}

Table 3 showed that elementary school teachers has an inadequate of overall knowledge of asthma when all theoretical items taken together. In fact, the study found that $94.1 \%, 97.7,79.5 \%, 88.3 \%$, and $95.4 \%$ of participants have poor knowledge regarding etiology, pathophysiology, triggers, management of asthma, and support for asthma, respectively. While the knowledge related to general information (86.6\%) about asthma, severity (93.1\%), and signs and symptoms (96.1\%) appeared adequate. While asking "do you think that you have adequate knowledge about asthma?" most of the teachers think they have knowledge; however, opposite results have been obtained while testing. Table 4 has shown that majority of participants failed to perform the tasked they were asked to do. 
Table 3. Aadequate of Asthma Knowledge among Primary School Teachers $(n=4000)$

\begin{tabular}{|c|c|c|c|c|c|c|}
\hline \multirow{2}{*}{ Knowledge Items } & \multicolumn{2}{|c|}{ Inadequate $\leq \mathbf{5 0} \%$} & \multicolumn{2}{|c|}{ Moderately adequate 51-69 } & \multicolumn{2}{|c|}{ Adequate $\geq 70$} \\
\hline & $\mathrm{N}$ & $\%$ & $\mathrm{~N}$ & $\%$ & $\mathrm{~N}$ & $\%$ \\
\hline General Information & 412 & $10.30 \%$ & 116 & $2.90 \%$ & 3464 & $86.60 \%$ \\
\hline Etiology & 3764 & $94.10 \%$ & 168 & $4.20 \%$ & 64 & $1.60 \%$ \\
\hline Pathophysiology & 3908 & $97.70 \%$ & 12.8 & $0.32 \%$ & 76 & $1.90 \%$ \\
\hline Severity & 128 & $3.20 \%$ & 140 & $3.50 \%$ & 3724 & $93.10 \%$ \\
\hline Signs and Symptoms & 100 & $2.50 \%$ & 48 & $1.20 \%$ & 3844 & $96.10 \%$ \\
\hline Asthma Attacks & 336 & $8.40 \%$ & 3076 & $76.90 \%$ & 584 & $14.60 \%$ \\
\hline Triggers & 3180 & $79.50 \%$ & 688 & $17.20 \%$ & 128 & $3.20 \%$ \\
\hline Management of Asthma & 3532 & $88.30 \%$ & 376 & $9.40 \%$ & 88 & $2.20 \%$ \\
\hline Asthma and Support & 3816 & $95.40 \%$ & 116 & $2.90 \%$ & 64 & $1.60 \%$ \\
\hline Overall knowledge & 3284 & $82.10 \%$ & 492 & $12.30 \%$ & 220 & $5.50 \%$ \\
\hline
\end{tabular}

Table 4. Percentage of Success and Failed Task of Test Scenario Items among Elementary School Teachers $(\mathrm{n}=4000)$

\begin{tabular}{|c|c|c|c|c|}
\hline Task to Perform & $\begin{array}{l}\text { Number of Teacher who } \\
\text { Fulfilled the Task Correctly }\end{array}$ & $\begin{array}{l}\text { Success } \\
\text { Rate }\end{array}$ & $\begin{array}{c}\text { Number of Teacher who } \\
\text { Failed the Task }\end{array}$ & $\begin{array}{l}\text { Failed } \\
\text { Rate }\end{array}$ \\
\hline $\begin{array}{l}\text { Correct assessment of signs of } \\
\text { asthma }\end{array}$ & 675.2 & $16.88 \%$ & 3324 & $83.10 \%$ \\
\hline $\begin{array}{l}\text { Correct starting time for } \\
\text { asthma first aid }\end{array}$ & 504 & $12.60 \%$ & 3492 & $87.30 \%$ \\
\hline $\begin{array}{l}\text { Performance of correct } \\
\text { recovery position }\end{array}$ & 192 & $4.80 \%$ & 3804 & $95.10 \%$ \\
\hline Correct Usage of puffer & 3882.8 & $97.07 \%$ & 116 & $2.90 \%$ \\
\hline Time Waiting for Improvement & 972 & $24.30 \%$ & 3024 & $75.60 \%$ \\
\hline If there is still no improvement & 76 & $1.90 \%$ & 3922 & $98.05 \%$ \\
\hline $\begin{array}{l}\text { Giving correct information for } \\
\text { the emergency call }\end{array}$ & 3608 & $90.20 \%$ & 388 & $9.70 \%$ \\
\hline
\end{tabular}

\section{Discussion}

The present study revealed that not many school teachers or health nurses were aware about how to tackle situations that are in accordance with asthmatic attack. A study was taken into account in order to investigate different behaviors that leads to severe health related problems in Egypt. The findings illustrated that adolescents in Egypt tend to engage in behaviors that pose risks to their health (Albuhairan et al., 2015). It is of utmost importance that parents, school health nurses, educators become aware of such consequences and work in accordance to mitigate or prevent them (Lundy \& janes, 2016).

The adequate management of asthma in schools is a significant step in helping children with asthma to achieve optimum disease control. A study conducted by Jaramillo and Reznik (2015) revealed that teachers do not receive adequate training on the asthma management of the students. The teachers need to be fully prepared to meet the children's requirement within the classroom. Another study was taken into account to examine the effects of programs that are in association with asthma education. For this study, pre-test-post-test randomized controlled design was used. School teachers were randomly assigned to either experimental group or control group. The outcome revealed that teachers, who were associated with experimental group, had more knowledge regarding asthma as compared to those who were in control group (Kawafha \& Tawalbeh, 2015).

A study was conducted in order to determine asthma awareness among primary school teachers in Zanjan, Iran. The mean level of awareness among the primary school teachers was found out to be good. A significant 
relationship of teachers was seen with the history of dealing with asthmatic children (Mohammadzadeh et al., 2017). Another study was taken into consideration; this study was conducted to examine the perception of teachers in terms of supporting pupils with long-term conditions, teachers training, and intervention in accordance to enhance their knowledge regarding long-term conditions. The results revealed that teachers received limited training in accordance with long term condition management (Hinton \& Kirk, 2015). Lack of asthma education and training are the main reasons for deficient knowledge among the Jordanian school teachers Kawafha \& Tawalbeh (2015).

Knowledge of first aid for asthma is significant for every individual as it constituted the lifesaving treatments for unexpected illness and injuries. A study revealed that deficiency of knowledge among teachers is due to lack of training, limited educational resources, and workload at school (Kawafha \& Tawalbeh, 2015). A study was conducted to evaluate the effects of asthma educational program among primary school teachers of Saudi Arabia and their ability to deliver their assistance in asthma related situations. The findings revealed that higher proportion of teachers were confident enough in terms of providing care to children with asthma. It was due to their history with such children. Moreover, the study suggested that educational programs can be effective in terms of training teachers and in enhancing their knowledge (Al Aloola et al., 2017). However, in Jordan, the primary school teachers are only responsible for managing the patients with asthma because there are no school nurses, available in Jordanian schools (Kawafha \& Tawalbeh, 2015). The educational programs are helpful for the teachers and nurses in gaining significant knowledge about asthma to reduce the complications associated with asthmatic children.

A study was conducted to investigate training and level of practices that are required for asthma and its management among primary school teachers of Jordan. However, the results illustrated that all the teachers have positive attitudes towards children with asthma, but very few of these teachers were trained to provide first aid intervention to manage asthmatic situations. In addition, the study suggested that educational and health needs were not met in public schools; and therefore, it is difficult to go about intervention for such children (Abu-Hamour \& Al-Hmouz, 2017). Another study conducted by Cain and Reznik (2016) revealed the barriers that significantly contributed towards poor management of asthma by the school teachers. These factors include lack of knowledge regarding asthma management, limited communication among the school staff, and insufficient access to asthma medication in the school. On the other hand, a study conducted by Pitstick (2015) stated that $85 \%$ of the teachers showed interest to learn training regarding asthma management. Teachers, who are not aware about asthma, usually feel that their intervention would jeopardize children's health rather than improving it. However, there are cases where students with asthma are not considered as eligible for attaining special education in public schools of Jordan. A study revealed that this is because many advanced practices are not understood and implemented in the public schools of Jordan (Abu-Hamour \& Al-Hmouz, 2014).

The theoretical knowledge awareness about asthma is significant among teachers to determine the children's experience with chronic illness. Chronic diseases; like asthma, affect the daily life of students that resulted in life threatening events in classroom. Despite of recognizing the importance of asthmatic management, some teachers were concerned about giving emergency medical care to children, suffering asthmatic attack in the classroom. The results suggested that the school teachers need to be well-prepared for the management of asthma by the implementation of health and educational programs. The teachers should have adequate knowledge about asthma for promoting the health status of school children.

\section{Acknowledgements}

The author is very thankful to all the associated personnel in any reference that contributed in/for the purpose of this research.

\section{Competing Interests Statement}

The authors declares that there are no competing or potential conflicts of interest.

\section{References}

Abu-Hamour, B., \& Al-Hmouz, H. (2014). Special education in Jordan. European Journal of Special Needs Education, 29(1), 105-115. https://doi.org/10.1080/08856257.2013.859820

Abu-Hamour, B., \& Al-Hmouz, H. (2017). Practices of Primary School Teachers in Supporting Students with Asthma in Jordan. Meta-cognitive Strategies in Problem Solving for Children with Learning Difficulties in Mathematics at the Primary Level, 37, 32(1), 180.

Al Aloola, N. A., Saba, M., Nissen, L., Alewairdhi, H. A., Alaloola, A., \& Saini, B. (2017). Development and 
evaluation of a school-based asthma educational program. Journal of Asthma, 54(4), 419-429. https://doi.org/10.1080/02770903.2016.1218015

Albuhairan F, Tamim H, Al Dubayee M, AlDhukair S, Al Shehi S, Tamimi W et al. (2015). Time for an adolescent health surveillance system in Saudi Arabia: findings from 'Jeeluna'. J Adolesc Health, 57, 263-269. https://doi.org/10.1016/j.jadohealth.2015.06.009

Asthma Australia. (2018). Working with your local Asthma Foundation. Retrieved from https://www.asthmaaustralia.org.au/

Basheti, I. A., Hamadi, S. A., \& Reddel, H. K. (2016). Inter-professional education unveiling significant association between asthma knowledge and inhaler technique. Pharmacy Practice (Granada), 14(1), 0-0.

Cain, A., \& Reznik, M. (2016). Asthma management in New York City schools: A classroom teacher perspective. Journal of Asthma, 53(7), 744-750. https://doi.org/10.3109/02770903.2015.1135946

Hinton, D., \& Kirk, S. (2015). Teachers' perspectives of supporting pupils with long - term health conditions in mainstream schools: a narrative review of the literature. Health \& social care in the community, 23(2), 107-120. https://doi.org/10.1111/hsc.12104

Jaramillo, Y., \& Reznik, M. (2015). Do United States' teachers know and adhere to the national guidelines on asthma management in the classroom? A systematic review. The Scientific World Journal, 2015. https://doi.org/10.1155/2015/624828

Kawafha, M. M., \& Tawalbeh, L. I. (2015). The effect of asthma education program on knowledge of school teachers: A randomized controlled trial. Western journal of nursing research, 37(4), 425-440. https://doi.org/10.1177/0193945914528070

Lundy K, Janes S (2016). Community health nursing: caring for the public's health (3rd ed., pp. 345-360). USA: Jones \& Bartlett Company.

Ministry of Education. (2017). Retrieved from http://www.moe.gov.jo/Directorates/DirectoratesMenu Details.aspx ?MenuID $=270 \&$ DirectoratesID $=27$

Mohammadzadeh, I., Noori, H., Mazloomzadeh, S., Khodabandehlou, M., \& Ahmadiafshar, A. (2017). Asthma awareness among primary school teachers in Zanjan in 2014. Caspian Journal of Pediatrics, 3(2), 229-233.

National Asthma Council Australia. (2018). The National Asthma Council Australia. Retrieved from https://www.nationalasthma.org.au/

Patel, M., Pilcher, J., Reddel, H. K., Qi, V., Mackey, B., Tranquilino, T., ... \& Beasley, R. (2014). Predictors of severe exacerbations, poor asthma control, and $\beta$-agonist overuse for patients with asthma. The Journal of Allergy and Clinical Immunology: In Practice, 2(6), 751-758. https://doi.org/10.1016/j.jaip.2014.06.001

Patterson, M. P. (2014). What teachers need to know to support children with asthma in the preschool classroom (Doctoral dissertation, Oakland University).

Pitstick, C. (2015). Asthma knowledge among primary and secondary school teachers in rural northern Costa Rica. Cuadernos de Investigación UNED, 7(1), 25-32. https://doi.org/10.22458/urj.v7i1.858

Reddel, H. K., Hurd, S. S., \& FitzGerald, J. M. (2014). World Asthma Day. GINA 2014: a global asthma strategy for a global problem. The International Journal of Tuberculosis and Lung Disease, 18(5), 505-506. https://doi.org/10.5588/ijtld.14.0246

United States Department of Health and Human Services, Centers for Disease Control and Prevention, National Center for Health Statistics [USDHHS, CDC]. (2016). Asthma. Retrieved from https://www.cdc.gov/nchs/fastats/asthma.htm

World Bank. (2014). National Education Profile 2014 Update. Retrieved from https://www.epdc.org/sites/default/files/documents/EPDC\%20NEP_Jordan.pdf

\section{Copyrights}

Copyright for this article is retained by the author(s), with first publication rights granted to the journal.

This is an open-access article distributed under the terms and conditions of the Creative Commons Attribution license (http://creativecommons.org/licenses/by/4.0/). 